\title{
Performance Appraisal of Open-ended Equity Funds in Pakistan: An alternative Approaches of Performance Measure
}

\author{
Syed Zakir Abbas Zaidi* \\ Bahria University, Karachi, Pakistan
}

\begin{abstract}
There are more than one hundred portfolio performances, which have been proposed in financial literature, (Cogneau and Hübner, 2009), but extensively used performance measure is a Sharpe ratio and in Pakistan Asset Management Companies (AMCs) also prefer to exhibit their performance in Sharpe ratio. However, financial literature has ample of evidence that recommend Sharpe ratio is valid under normal distribution of returns. The financial returns are not distributed normally as result of which standard deviation may not adequately measure risk (Bodie et al., 2009). Whereas, standard deviation of negatively skewed distribution underestimates and positively skewed overestimates volatility that would be misleading Sharpe index. In this study, we concluded that for skewed and non-normal distribution Omega ratio or Sharpe-Omega are alternative performance measures.
\end{abstract}

\section{Introduction}

Historically, mutual fund as a mean of investment started functioning about two centuries ago in Europe and the USA. Europeans have been practicing it since 1800s and Americans since 1890s. In those days, these funds were close-ended funds that had fixed number of shareholders. In 1924 in USA first open-ended fund was launched by Massachusetts Investors Trust and this fund still exists (Burrows, 2013).

There has been phenomenal boom in mutual funds industry witnessed all over the world as result of great interest and demand for investment in mutual funds by investors. Since the main focus of finance suggests evaluating fund manager's ability to maximize return by keeping risk at minimum level. Therefore, to achieve this end practitioner and academician brought in numerous measuring tools to estimate portfolio that yields maximum return and minimum risk (Kapsos et al., 2014). Within context methods to measure performance were studied widely and number of methods of evaluation has been developed to measure portfolio performances.

In Pakistan, National Investment (Unit) Trust (NIT) is a pioneer of Mutual Funds industry licensed by the Security Exchange Commission of Pakistan as a non-banking finance company in 1962, and in the same year it issued first open-ended mutual fund. Guide Mutual Fund. Asset Management Companies are bound to invest at least $70 \%$ of their net assets in listed equity assets in case of equity fund and rest to be invested in cash or near cash instruments (Nafees et al., 2011).

*Corresponding author.

Email: zakirabbas.bukc@bahria.edu.pk 
Mutual Fund Industry of Pakistan showed encouraging results and added value, however, at the same time some of these funds have not been able to perform well due to diversification problem (Shah and Hijazi, 2005). At present there are 184 mutual funds in Pakistan out of which 164 open-ended funds, 3 close-ended and 17 are pension funds. Within the open-ended funds, there are 21 categories like money market fund, income fund, equity funds capital protected funds and other types of funds (MUFAP, 2010).

These funds are managed by professional managers by investing investor's money into stocks, bonds, short-term money market instruments and in other securities. In this process, they realized capital gain/loss and dividend (on stocks), interest (on bonds \& sort-term money market instruments). These proceeds pass on to investors in form of Net Asset Value (NAV). NAV which is value of share in mutual fund is computed on daily basis (Gandhi and Perumal, 2016). The idea behind fund performance analysis is that whether fund managers offer investors value for money. Since, investor bears certain cost like opportunity cost of poorly diversified portfolio, transaction cost and management fee, therefore, fund manage should have sufficient skills to compensate for all these costs (Amin and Kat, 2003).

The main task of fund managers is to maximize wealth of investors, whereas the focus of risk controllers is to minimize risk. Both views are relevant and pertinent, therefore, mere maximizing return is not sufficient but we must consider the quality of return by resolving this conflict of risk \& return (Bacon, 2008).

More than a hundred analytical methods are there which can compute portfolio performance or fund manager performance and each one has its own strengths and weaknesses and categorized as asset selection vs. market timing, standardized vs. individualized, absolute vs. relative and excess return vs. gain measure (Cogneau and Hübner, 2009). Caporin et al. (2014) summarized the performance measuring methods into a family of four, namely, "Measures of Relative Performance, Measures of Absolute Performance, Measures explicitly based on the Return Distribution and Measures directly derived from Utility Functions."

Sharpe ratio that belongs to first method of families of four is based on mean-variance theory and validity can only be confirmed when distribution is normal or Gaussian. Performance in mean-variance analysis can be improved significantly with the application of appropriate weights and rebalancing them periodically (ZAIDI et al., 2017). A simple assumption of Gaussian distribution may lead to an underestimate of the portfolio total risk (Amin and Kat, 2003; León et al., 2015).

Other than mean and Standard deviation all other moments are known as higher moments and important ones are skewness and kurtosis. Omega incorporates all the moments of the distribution as it is a direct transformation of it (Bacmann and Scholz, 2003).

Recently suggested measure by Keating and Shadwick (2002), which they termed "Omega Ratio" is computed by partitioning the whole distribution into two i.e. one which is above the threshold and second below the threshold. Returns that exceed threshold are considered as profit and other which are less than the threshold considered as losses (Kapsos et al., 2014).

Omega function is a smooth downward sloping curve from $(a, b)$ onto $(0, \infty)$ from which it follows that it takes the value 1 precisely once (when MAR is equal to mean of data) (Keating and Shadwick, 2002).

Avouyi-Dovi et al. (2004) stated that the Omega has fine properties that integrate all the moments of the distribution and it considers the investor's set threshold; furthermore, Omega is computed directly from return distribution. No additional assumptions are required for neither risk preferences nor utility function only a simple decision rule is required to define.

De Wet et al. (2009) also concluded that shape of distribution doesn't matter as far as mea- 
surement of Omega and empirical results confirm that Sharpe ratio and Omega ratios are quite different from each other when distributions is non-normal and both ratios are similar when distribution is symmetric.

There are two interesting properties of Omega ratio while ranking the portfolio; first when minimum acceptable return (threshold) is set equal to the mean of the distribution, the Omega ratio is one. Second property is that it can rank investment even with negative threshold, whereas, it cannot be possible to rank with negative ratio in case of Sharpe ratio. Further, investors like probability of more positive returns or statistically positive skewness and dislike negative skewness and high kurtosis (skewness \& kurtosis are higher moments and mean \& standard deviation first two moments) (Bacmann and Scholz, 2003).

The minimum acceptable ratio (MAR) that serve the purpose of threshold in computing the Omega ratio is critical in a sense that if it is too high it may portray the sound investment as an unfavorable one and if it is too low it will not adequately capture the risks that concern the investor. Some studies recommends using risk free rate as a MAR (Boudt et al., 2012).

Several of these alternative performance measures, however, fall short of having firm theoretical foundations (considering the Sharpe ratio is based on the expected utility theory) and do not permit accurate ranking of portfolio performance given that ranking based on these measures depends significantly on the choice of threshold.

As Van Dyk et al. (2014) observed that other than Sharpe ratio, several alternative performance measures don't have firm theoretical base; whereas, foundation of Sharpe ratio is based on the expected utility theory. Gaspars-Wieloch (2015) introduced the Sharpe-Omega with some variation that maintains all of its desirable features, provides the same information as Omega and always ranks investments the same as Omega (Van Dyk et al., 2014).

\subsection{Research Gap}

As far as Pakistani context is concerned, no study has been found that suggests alternative method, especially, when distribution don't take Gaussian bell shape. Hence, to fill this gap, we undertook tests necessary to ascertain whether returns are normally distributed or not and after applying all standard statistical tests found that returns (NAV) are not normality distributed. In the second phase, we presented alternative performance or ranking methods that work perfectly even under higher moments.

\section{Literature Review}

\subsection{Mutual Fund in Historical Perspective}

Historically, mutual fund traces its roots since 1800s in Europe and the USA Historically, mutual fund as a mean of investment started functioning about two centuries ago in Europe and the USA. Europeans have been practicing it since 1800s and Americans, since 1890s. In those days, these funds were close-ended funds that had fixed number of shareholders. However, in 1924 in USA first open-ended fund was established namely, Massachusetts Investors Trust and this fund still exists (Burrows, 2013). 


\subsection{Development of Mutual Fund in Pakistan}

In Pakistan, National Investment (Unit) Trust (NIT) is a pioneer of Mutual Funds industry licensed by the Security Exchange Commission of Pakistan as a non-banking finance company in 1962, and in the same year it issued first open-ended mutual fund. Guide Mutual Fund. Asset Management Companies are bound to invest at least $70 \%$ of their net asset in listed equity assets in case of equity fund and rest to be invested in cash or near cash instruments Nafees et al. (2011).

Mutual Fund Industry of Pakistan showed encouraging results and added value, however, at the same time some of these funds have not been able to perform well due to diversification problem Shah and Hijazi (2005).

Mutual Funds Association of Pakistan (MUFAP) is the trade body for Pakistan's multi billion rupees asset management industry. Every Asset Management Company (AMC) is required to prepare a monthly Fund Managers Report (FMR) wherein has to report their performances indicator as per SECP's Circular No. 16 dated July 07, 2010 (MUFAP, 2010).

\subsection{Expectation of Better Returns}

Investors prefer fund managers who provide better returns to their investment. Amin and Kat (2003) stated that the idea behind fund performance analysis is to evaluate whether fund managers offer investors value for money. Since, investors bear certain cost like opportunity cost of poorly diversified portfolio, transaction cost and management fee, therefore, fund manager should have sufficient skills to compensate for all these costs. Bacon (2008) said that Performance measurement is a key function in an asset management firm and the main task of fund managers is to maximize wealth of investors, whereas the focus of risk controllers is to minimize risk. Both views are relevant and pertinent, therefore, mere maximizing return is not sufficient but we must consider the quality of return by resolving this conflict of risk \& return (Gandhi and Perumal, 2016).

These funds are managed by professional managers by investing investor's money into stocks, bonds, short-term money market instruments and in other securities. In this process, they realize capital gain/loss and dividend (on stocks), interest (on bonds \& sort-term money market instruments). These proceeds pass on to investors in form of Net Asset Value (NAV). NAV which is value of share in mutual fund is computed on daily basis.

Feibel (2003) and Gay et al. (2014) stated that rolling period return analysis is considered by experts as stronger and reliable return analysis. In this analysis, we break many periods into smaller and overlapping periods. Wherein we compute returns for fixed frame of time by adding new period and dropping earlier period.

\subsection{Categorization of Mutual Fund Performance Measures}

There are more than a hundred analytical methods which can compute portfolio performance or fund manager performance and each one has its own strengths and weaknesses; these methods have been categorized as asset selection vs. market timing, standardized vs. individualized, absolute vs. relative and excess return vs. gain measure Caporin et al. (2014). Steinki and Mohammad (2015) posited that there are five popular performance ratios, i.e. Calmar Ratio, Omega, Sharpe Ratio, Sortino Ratio and Treynor Ratio. 


\subsection{Non-Normal Financial Returns}

Testing the normality of returns distribution is pivotal while stating performance by using Sharpe ratio, however, ample of studies state evident of non-normality. For example, Aggarwal et al. (1989) exhibit that Japanese stock market showed evidence of significant presence of skewness kurtosis in its monthly returns. Researchers use certain tests to arrive at conclusion about normality of data by employing numerical methods like skewness and kurtosis indices, graphical methods (histograms, boxplots, Q-Q-plots) and four formal tests of normality: Shapiro-Wilk (SW) test, Kolmogorov-Smirnov (KS) test, Lilliefors (LF) test and Anderson-Darling (AD) test Razali et al. (2011).

\subsection{Weaknesses of Sharpe Ratio under Non-Normal Return Distribution}

Since Sharpe ratio follows mean-variance model and is based on assumption of normally distributed returns, however, positive or skewness fatter tail is commonly observed in financial return distribution (De Wet et al., 2009). The assumption of normality drew criticism from analysts and recent international papers have highlighted that return distributions are not necessarily normal; especially in the context of increasing acceptance of options, futures and hedge funds in portfolios have led to probability distributions that are far from normal. Hence, Sharpe ration inadequately account for all risk to which investor are exposed (Bacmann and Scholz, 2003; León et al., 2015). Validity can only be confirmed when distribution is normal or Gaussian. Performance in mean-variance analysis can be improved significantly with the application of appropriate weights and rebalancing them periodically (Zakamouline and Koekebakker, 2009).

\subsection{Alternative to Sharpe measure, Omega and Sharpe-Omega}

The current study used Omega $(\Omega)$ as a performance evaluation measure, which accomplishes the task of incorporating all of the higher moments of a returns distribution. It provides a full characterization of the risk reward characteristics of the distribution in a way which is intuitively appealing and easily calculated Keating and Shadwick (2002). Instead of estimating any individual moments it measures their total impact, which is of course precisely what is of interest to practitioners. It was developed to overcome the shortcoming of Sharpe ratio which arises due to standard deviation of non-normal distribution. An important feature of Omega is that it is not plagued by sampling uncertainty, unlike standard statistical estimators-as it is calculated directly from the observed distribution and requires no estimates.

It also provides a risk-reward evaluation of a returns distribution which incorporates the beneficial impact of gains as well as the detrimental effect of losses, relative to any individual's loss threshold (Bertrand and Prigent, 2014).

Omega ratio, as it was named by Keating and Shadwick (2002) is a ratio of whole distribution portioned into two - one that is above the threshold and second below the threshold. Returns exceeding the threshold are considered as profit and which are less than the threshold considered as losses Kapsos et al. (2014).

Avouyi-Dovi et al. (2004) postulated that the Omega has fine properties that integrate all the moments of the distribution and it considers the investor's set threshold; furthermore, Omega is computed directly from return distribution. No additional assumptions are required for risk preferences or utility function only a simple decision rule is required to define. Van Dyk et al. (2014) described it a Performance measures based on lower partial moments (LPMs) and it indirectly adjusts for both skewness and kurtosis. Bertrand and Prigent (2011) stated that main 
advantage of Omega ratio is that at any level of threshold, ranking is always possible and achievable even if distribution is skewed or kurtosis.

Gupta and Kazemi (2008) presented their study and in this study, they showed that Omega is ratio of call and put price and intuitively explained what it is and what are its limitation. Secondly, one can trace its roots from call and put option. Moreover, vast literature in option pricing can help to estimate precise Omega and better understanding of its properties. This paper present new version of Omega, named as Sharpe-Omega, which provides same information as of Omega but in formulation familiar to Sharpe ratio.

\section{Methodology}

\subsection{Sample Schemes}

In this study, we have adopted purposive sampling and the elementary purpose was to draw the inferences based on reliable samples (extracted from Mutual Funds Association of Pakistan (MUFAP)) which are in existence during whole study period i.e. year 2007-2017. We have evaluated data of twenty equity mutual funds pertaining to fourteen Asset Management Companies (AMCs) and PSX-100 index (formerly known as KSE-100 index) as benchmark. Net Asset Value (NAV) of open-ended equity funds of these AMCs taken since the inception ranging from 2006-06-30 to 2016-06-30.

\subsection{Sources of Data}

We employed secondary source of data. The data of NAV, dividends and Ex-Dividend NAV obtained from the website of Mutual Fund Association of Pakistan (MUFAP). Data pertains since inception of fund to December 31, 2016 of each AMC, T-bill data obtained from the website of State Bank of Pakistan (SBP) and data pertaining to market index (Pakistan Stock Exchange -PSX) is obtained from the website of Business Recorder.

\subsection{Models}

\subsubsection{Sharpe Ratio}

Sharpe ratio, also known as the reward-to-volatility ratio was proposed by William Sharpe and since then used extensively all over the world to evaluate performance of fund managers. Sharpe ratio (for portfolios) = where numerator of Sharpe ratio is excess return (annualized return of fund over minus risk free return) and denominator of this ratio is annualized Standard Deviation of excess return. The criterion is higher the output higher the rank. Since the Sharpe ratio penalized equally downward and upward volatility, whereas investors are more concerned about downward volatility. However, Sharpe ratio is only valid for either normal distribution or quadratic preferences Zakamouline and Koekebakker (2009).

Furthermore, it is a well-established fact that some of financial instruments return distributions from normality are statistically significant and in that case the standard deviation underestimates the total risk and generates biased investment rankings León et al. (2015). 


\subsubsection{Omega Ratio}

Problem with financial returns is that these are not normally distributed and skewness \& kurtosis present in it Aggarwal et al. (1989). There are several researchers who exposed existences of skewness and kurtosis in empirical asset return distributions (Arditti, 1967; Cootner, 1964; Fama, 1965).

The dissimilarity between Omega and Sharpe is that former take into account for all moments and latter is influenced by the first two moments. Omega as an alternative to Sharpe was developed by Keating and Shadwick (2002) to improve deficiencies of traditional performance measure that are used to apply on non-normal distributed return distributions (GasparsWieloch, 2015).

Main advantage of Omega ratio is that at any level of threshold, ranking is always possible and achievable even if distribution is skewed or kurtosis Bertrand and Prigent (2006) by slicing the returns into losses and gains above and below the threshold. In contrast to Sharpe ratio (which rely on mean-variance model), Omega loss threshold is a function of the investor's preferences. Formula of Omega is as follow,

$$
w(r)=\frac{\int_{r}^{b}(1-F(x) d x}{\int_{a}^{r}(1-F(x) d x} \text { or } \frac{\text { UpsidePotential }}{\text { DownsidePotential }}
$$

Where:

- $\mathrm{F}(\mathrm{x})$ is the cumulative distribution of returns

- $(a, b)$ represents the interval of returns

- $r$ is the threshold level set

- is the probability-weighted ratio of gains to losses relative to the threshold

$$
\begin{aligned}
& p=K e^{-r T} \times N\left(-d_{2}\right)-S_{0} \times N\left(-d_{1}\right) \\
& p=K e^{-r T} \times N\left(-d_{2}\right)-S_{0} \times N\left(-d_{1}\right)
\end{aligned}
$$

\subsubsection{Sharpe-Omega Ratio}

Where:

1. $F(x)$ is the cumulative distribution of returns

2. $(a, b)$ represents the interval of returns

3. $r$ is the threshold level set

4. $\omega(r)$ is the probability-weighted ratio of gains to losses relative to the threshold $r$ 


\subsubsection{Sharpe-Omega Ratio}

Black-Scholes Equation

$$
p=K e^{-r T} \times N\left(-d_{2}\right)-S_{0} \times N\left(-d_{1}\right)
$$

Where:

1. $N($.$) is the cumulative distribution function of the standard normal distribution.$

2. $T$ is the time to maturity (expressed in years).

3. $S_{t}$ is the spot price of the underlying asset.

4. $K$ is the strike price.

5. $r$ is the risk-free rate (annual rate, expressed in terms of continuous compounding).

6. $\sigma$ is the volatility of returns of the underlying asset.

Sharpe-Omega equation as suggested by Caporin and Lisi (2009), made some changes to original Black-Scholes equation and derived formula for Sharpe-Omega from following equation.

$P(L)=\exp \left(L-r_{f}\right) N\left(-d_{2}\right)-\exp \left(x-r_{f}\right) N\left(-d_{1}\right)$ and formula is:

$E^{r f}(\Omega(L)-1)=x-L / e-{ }^{r f} E[\max (L-x, o)]$

Where,

1. $x$ is the expected continuously compounded per period rate of return on the investment

2. $L$ is threshold

3. $r f$ is risk free rate

4. $P(L)$ is put option and initial price 1

5. $\exp (L)$ is exercise price

Sharpe-Omega ratio is determined by taking subset of the returns that are more than the threshold and take the differences of those to the target. We sum the squares and divide by the total number of observations of entire series $(n)$

\section{Empirical Results}

In this section, we have described performance of fund managers by showing what value they have added to investment of investors. Where, we discussed calendar year returns, annualized return and cumulative returns to estimate their efficiencies. As we are not only interested in value these funds added, but wanted to know at what cost these returns were achieved by measuring volatility and validity of volatility. For this purpose, we tested the normality of distribution by applying different statistical tests. 


\subsection{Calendar Year Returns}

Following table exhibits how much value is added by fund managers for the years 2009, 2012 and 2016 and 2017. Returns are calculated as NAV at the end of the year minus NAV at beginning of the year divided by beginning of the year NAV. Calendar Return $=\mathrm{NAV}_{\text {ending }^{-}}$ NAV beginning / NAV Beginning. The highest returns were produce by ATSM \& HBEF in the year 2009, however, 2008 was a bad year for the whole mutual fund industry. First row pertains to KSE-100 index and is shown for the sake of comparison, NAFA beat the index in the year 2007, ATSM, HBEF, MPSM and USAF in 2009, AKOP and NAFA in 2012, NIUF in 2014, AKOP, JSFE, JSLF and USAF in 2015, AKOP in 2016 and in the year 2017 except ASKF, ATSM, FCMF all other performed well as far as calendar returns are concerned.

Table 4.1: Calendar Returns

\begin{tabular}{lcccccccccccc}
\hline & 2007 & 2008 & 2009 & 2010 & 2011 & 2012 & 2013 & 2014 & 2015 & 2016 & 2017 \\
\hline INDX & 24.9 & -58.3 & 60.0 & 28.1 & -5.6 & 49.0 & 49.4 & 27.2 & 2.1 & 45.7 & 5.8 \\
ABSF & NA & NA & 29.7 & -4.5 & -21.5 & 24.8 & 4.6 & 2.7 & 1.7 & 42.2 & 11.0 \\
AKOP & NA & -40.7 & 53.3 & -27.0 & -12.8 & 65.9 & 25.8 & 13.8 & 17.7 & 47.0 & 7.8 \\
ALPF & NA & NA & 19.6 & 16.7 & -19.4 & 8.1 & 31.2 & 2.5 & 5.1 & 22.1 & 11.9 \\
ALSF & NA & -3.0 & 43.9 & -12.8 & -17.3 & 25.3 & 3.8 & -10.0 & 5.1 & 28.1 & 11.7 \\
ASKF & NA & NA & NA & NA & NA & 13.5 & 0.8 & 5.6 & -14.8 & 26.4 & 2.6 \\
ATSM & 2.8 & -36.8 & 103.9 & -12.4 & -23.6 & 36.1 & 11.1 & 4.4 & -7.5 & 48.1 & 7.6 \\
FCMF & 11.6 & -58.8 & 68.0 & 0.6 & -3.7 & 16.9 & 22.3 & 12.4 & -13.3 & 28.7 & 3.6 \\
FHSF & NA & NA & 1.1 & 11.7 & -20.0 & 28.3 & 0.2 & -1.6 & -14.7 & 30.4 & 6.5 \\
HBEF & 5.3 & -58.0 & 104.2 & 16.3 & -23.6 & 25.9 & 33.7 & -16.3 & 1.9 & 36.3 & 13.1 \\
HBEQ & NA & NA & NA & NA & -5.9 & 24.9 & 15.7 & -8.2 & 0.2 & 6.4 & 10.7 \\
HBSF & 0.1 & -23.3 & 60.9 & 4.9 & -11.0 & 25.9 & 15.8 & -14.4 & -9.6 & 29.6 & 9.6 \\
JSFE & 41.1 & -46.6 & -11.9 & -1.7 & -13.2 & 43.1 & 34.9 & 3.2 & 3.4 & 36.2 & 7.7 \\
JSGF & -3.0 & -59.0 & 51.0 & -1.6 & -24.5 & 45.3 & 28.7 & 0.5 & 0.0 & 40.8 & 11.1 \\
JSLF & 9.4 & -53.1 & 30.0 & 6.9 & -42.6 & 52.1 & 29.2 & 11.2 & 4.9 & 37.9 & 15.1 \\
LAKS & NA & NA & 1.8 & 16.1 & -22.0 & 28.5 & 16.1 & -7.4 & -19.4 & 39.4 & 9.0 \\
MPSM & -0.1 & -41.5 & 70.5 & -4.0 & -18.1 & 31.1 & 7.3 & 8.2 & 9.3 & 39.6 & 8.5 \\
NIUF & 23.0 & -44.2 & 34.7 & 2.7 & -17.6 & 28.2 & 49.9 & 32.8 & -4.2 & 38.4 & 10.3 \\
NAFA & 31.0 & -62.0 & 39.5 & 5.5 & -20.2 & 49.7 & 12.6 & 19.1 & 1.8 & 41.2 & 9.3 \\
USAF & 5.4 & -56.9 & 80.6 & -51.2 & -22.5 & 27.9 & 34.7 & 7.7 & 9.2 & 29.6 & 13.2 \\
\hline & & & & & & & & & & &
\end{tabular}

Table 1 depicts funds annualized return of nine years i.e. from 2009 to 2017 and constructed by taking end of year NAV minus beginning of year NAV, dividing by beginning of year NAV.

Rolling period analysis is considered by experts as stronger and reliable return analysis. 
In this analysis, we break many periods into smaller and overlapping periods. Wherein we compute returns for fixed frame of time by adding new period and dropping earlier period (Feibel, 2003; Gay, 2014). For example, in the following graph 7 years and 6 months returns of three funds are depicted comprising total 90 periods, e.g. Aug 09 to July 09 is one period, Sep 09 to Aug 11 second period, Oct 09 to Sep 11 third and so on. Hence, we can see over all AKOP shows upper returns in comparison to ABSF and ALPF except from Aug 10 to June 11 when AKOP plunged faster and greater than other two. On three occasions AKOP produced $60 \%$ annualized return i.e. Nov 09-Oct 10, Nov 12-Oct 13 and July 15-June16.

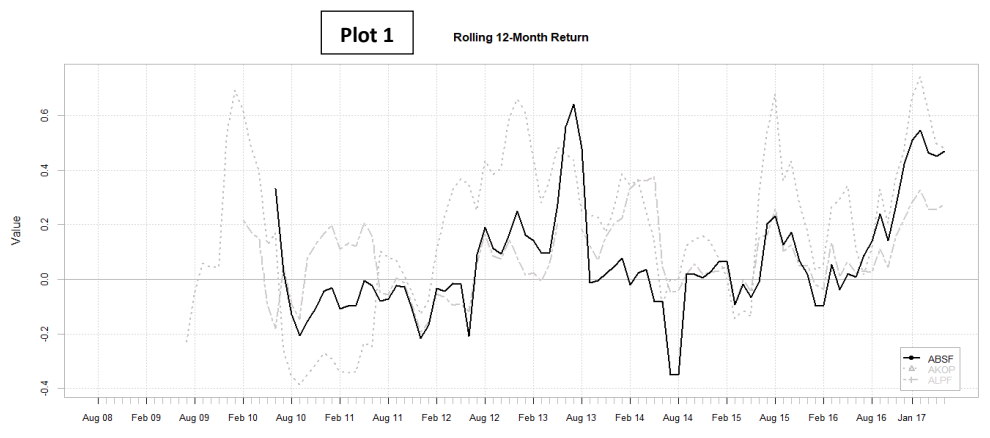

If we compare rolling returns with other measures of returns, it will portray more logical performance than to other measures. For example, annualized returns of funds AKOP, ABSF and ALSF are $15.3 \%, 13.2 \%$ and $9.7 \%$ respectively provided investor hold them from 2009 to 2017. Same is with cumulative returns and calendar years returns, former bespeak itself and latter is percentage change form start of year to end of year and in between what happened nothing can be traced.

\subsection{Cumulative Returns}

Table 2 and diagram presented cumulative return since inception of fund to date.

Table 4.2: Simple Annualized Returns

\begin{tabular}{lcccccccccc}
\hline ABSF & AKOP & ALPF & ALSF & ASKF & ATSM & FCMF & FHSF & HBEF & \\
\hline 0.132 & 0.153 & 0.133 & 0.097 & 0.075 & 0.109 & 0.062 & 0.056 & 0.089 & \\
\hline HBEQ & HBSF & JSFE & JSGF & JSLF & LAKS & MPSM & NIUF & NAFA & USAF \\
\hline 0.105 & 0.087 & 0.078 & 0.061 & 0.087 & 0.084 & 0.100 & 0.132 & 0.094 & 0.054 \\
\hline
\end{tabular}

Graphical representation of by applying the logic that how much Rupee one grown over this period is shown as under, for example AKOP yield annualized return =

$(1+2.5 / 1)^{1 / 9}-1=15 \%$ where $250 \%$ in decimal format is 2.5 

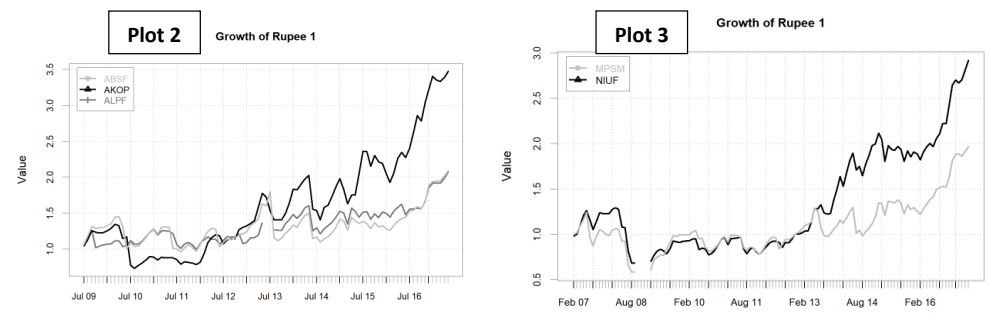

\subsection{Test of Normality}

Razali et al. (2011) suggested that Even though the graphical methods (Histograms, boxplot, Q-Q plot) and numerical methods (skewness and kurtosis indices) can serve as a useful tool in checking normality for sample of $\mathrm{n}$ independent observations, they are still not sufficient to provide conclusive evidence that the normal assumption holds. Therefore, in this study, we applied Shapiro-Wilk (SW) test along with Q-Q plot and numerical methods. For example, in the following graph it is evident that data set do not come from chosen distribution as points are not aligned along a line, (other are placed in appendix)
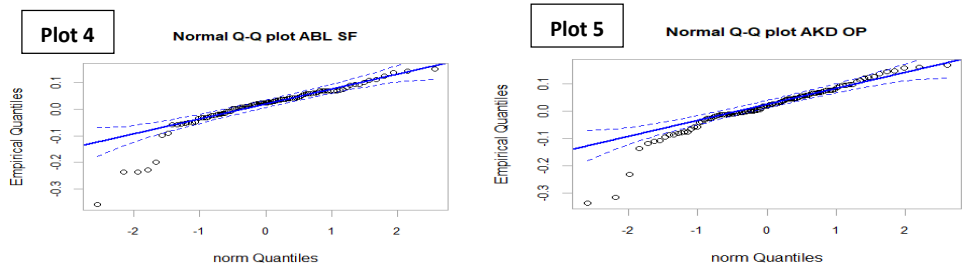

The simplest and in many ways, the best test of normality is QQ-plot which shows the empirical quantiles on $y$-axis and theoretical on $x$-axis. Large deviation from reference line indicates that data come from a population with a different distribution (Boudt et al., 2012). For example, Zakamouline and Koekebakker (2009) described that The Sharpe ratio can only be valid for either normally distributed returns or quadratic preferences. One commonly known and widely used method QQ plot is applied on data and their results depict that distribution is non-normal.

The skewness for a normal distribution is zero, and any symmetric data should have a skewness near zero. Negative values for the skewness as shown in the following table indicate that data are skewed left and left tail is longer than the right tail. The kurtosis for a standard normal distribution is three.

\subsection{Shapiro-Wilks Normality Test}

Shapiro-Wilks normality test is known as a powerful normality test and it rejects the hypothesis of normality when the p-value is less than or equal to 0.05 . If P-value is less than the alpha then we conclude that normality test failed and we say with $95 \%$ confidence that the data does not fit the normal distribution. The p-value exhibited in table 4 tells the chances are there that the sample comes from a non-normal distribution. 
Table 4.3: Skewness and Kurtosis

\begin{tabular}{lcccccccccc}
\hline & INDX & ABSF & AKOP & ALPF & ALSF & ASKF & ATSM & FCMF & FHSF & HBEF \\
\hline Skewness & -1.71 & -1.92 & -1.35 & -0.74 & -1.25 & -0.87 & -0.73 & -1.48 & -0.80 & -0.98 \\
Kurtosis & 7.73 & 5.61 & 3.94 & 1.74 & 3.75 & 2.13 & 2.30 & 7.06 & 1.07 & 6.43 \\
\hline Table 2 & HBEQ & HBSF & JSFE & JSGF & JSLF & LAKS & MPSM & NIUF & NAFA & USAF \\
\hline Skewness & -1.92 & -1.09 & -1.31 & -1.23 & -1.48 & -1.97 & -1.20 & -0.98 & -1.02 & -2.75 \\
Kurtosis & 5.70 & 4.15 & 2.88 & 4.06 & 5.14 & 7.09 & 3.09 & 1.75 & 5.26 & 13.91 \\
\hline
\end{tabular}

Table 4.4: Shapiro-Wilks

\begin{tabular}{cccccc}
\hline Fund & P-Value & $\mathbf{W}$ & Fund & P-Value & $\mathbf{W}$ \\
\hline ABSF & $1.539 \mathrm{e}-11$ & 0.80809 & HBSF & $6.167 \mathrm{e}-13$ & 0.76461 \\
AKOP & $8.832 \mathrm{e}-05$ & 0.94705 & JSFE & 0.0008821 & 0.95988 \\
ALPF & $4.437 \mathrm{e}-13$ & 0.75981 & JSGF & 0.004962 & 0.96857 \\
ALSF & $2.624 \mathrm{e}-13$ & 0.75201 & JSLF & 0.01853 & 0.97477 \\
ASKF & $3.463 \mathrm{e}-14$ & 0.72027 & LAKS & $4.634 \mathrm{e}-13$ & 0.76045 \\
ATSM & $1.425 \mathrm{e}-08$ & 0.88200 & MPSM & $8.64 \mathrm{e}-06$ & 0.93245 \\
FCMF & $3.185 \mathrm{e}-07$ & 0.90848 & NIUF & $2.435 \mathrm{e}-05$ & 0.93918 \\
FHSF & $2.682 \mathrm{e}-14$ & 0.71607 & NAFA & 0.00343 & 0.96677 \\
HBEF & $1.219 \mathrm{e}-08$ & 0.88056 & USAF & $5.596 \mathrm{e}-05$ & 0.94432 \\
HBEQ & $1.309 \mathrm{e}-13$ & 0.76461 & INDX & $5.057 \mathrm{e}-08$ & 0.89328 \\
\hline
\end{tabular}

\section{Performance Analysis}

\subsection{Empirical Cumulative Distribution Function (ECDF)}

Graphically, we can view the proportion higher or equal to MAR or lower to MAR by constructing an empirical cumulative distribution function (ECDF). Here we can see that the Omega divides the entire universe into two parts, one above threshold and other below the threshold. Best suited returns at this level of threshold are above the horizontal line (Bacmann and Scholz, 2003). In the following diagram, we assumed that investors threshold is $0.75 \%$ per month (which is equal to average T-Bills rate in Pakistan), we can use it to partition ECDF into two areas, say $\mathrm{G}$ and $\mathrm{L}(\mathrm{G}=\mathrm{Gain}$ and $\mathrm{L}=\mathrm{Loss})$, therefore, we can now compute (Omega) = G / L.

\subsection{Sharpe-Omega}

In this study, we show that Omega is ratio of call and put price and intuitively explains what it is and what its limitation are. Secondly, one can trace its roots from call and put option. 

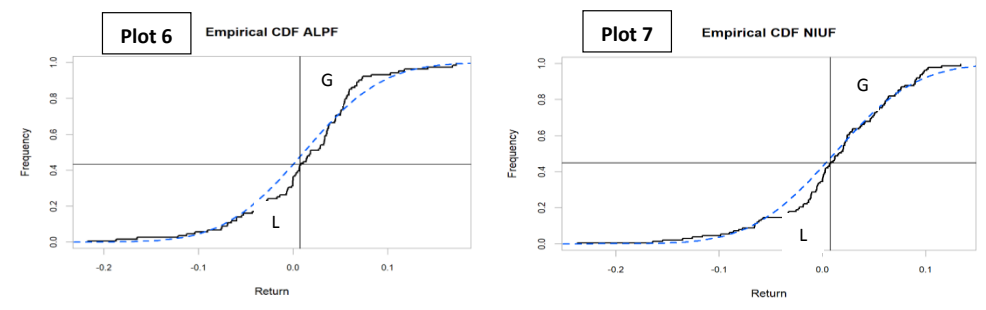

Additionally, vast literature in option pricing can help to estimate precise Omega and better understanding of its properties. This paper present new version of Omega, named as SharpeOmega, which provides same information as of Omega but in formulation familiar to Sharpe ratio. We portray side by side two graphs, one normal histogram with actual returns and other created by generating random variables to construct lognormal histogram. It shows that it fulfils the condition of lognormally distributed returns of investment and meet Sharpe-Omega formula by using Black-Scholes options as suggested by Gupta and Kazemi (2008).

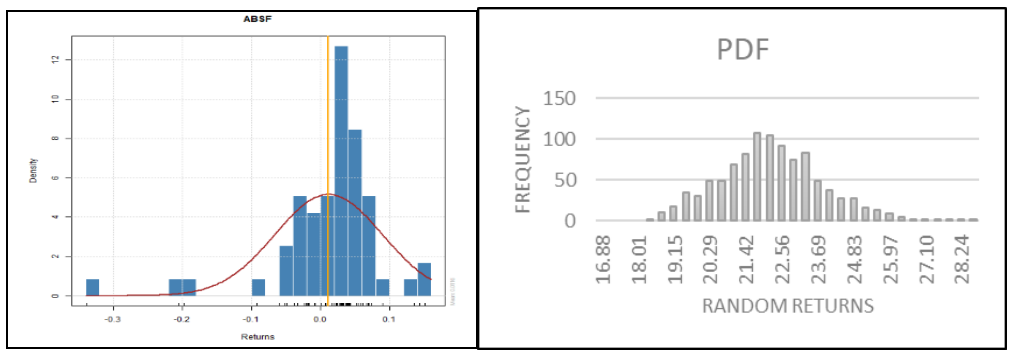

\subsubsection{Comparison}

In table 6, three rank measuring tools are used namely the Omega ratio, the Sharpe ratios and the Omega-Sharpe ratio to compare where Sharpe ratio deviate from the other two. These ratios are computed by setting risk-free and threshold at zero to compare ranking difference among these ratios. Gupta and Kazemi (2008) put forward Sharpe-Omega ratio and described it a better Omega, as it preserves all features of Omega and Sharpe. Hence, they formulized it as, Sharpe-Omega $=$ Expected return-Threshold / Put option price. Since Sharpe-Omega proportional to 1, there, it provides the same information and rank as of Omega. We sum the squares and divide by the total number of returns. We have added Omega-Sharpe ratio along with original treatment proposed by Keating and Shadwick (2002) for such comparison. In this table, Omega and Omega-Sharpe show the same ranking, while the Sharpe ratio has nine-point disagreement that is indication of high moment (zeros are disagreement and one are agreement as far as Omega and Sharpe measures comparison is concerned)

\subsection{Finding Risk}

Comparatively riskier fund can be found by drawing diagram on logarithmic scale and points where omegas cross are indifference points for choices between particular portfolio pair- 
Table 5.1: Ranking Comparison

\begin{tabular}{ccccccc}
\hline \multicolumn{2}{c}{ Omega } & \multicolumn{2}{c}{ Omega-Sharpe } & \multicolumn{2}{c}{ Sharpe } & Mapping \\
\hline 1.60 & NIUF & 0.6002 & NIUF & 0.610 & NIUF & 1 \\
1.56 & ALPF & 0.5638 & ALPF & 0.582 & ALPF & 1 \\
1.53 & AKOP & 0.5300 & AKOP & 0.527 & AKOP & 1 \\
1.50 & ABSF & 0.4958 & ABSF & 0.498 & ABSF & 1 \\
1.41 & HBEQ & 0.4104 & HBEQ & 0.428 & HBSF & 0 \\
1.40 & ATSM & 0.3988 & ATSM & 0.417 & ATSM & 1 \\
1.40 & HBSF & 0.3979 & HBSF & 0.408 & HBEQ & 0 \\
1.38 & MPSM & 0.3826 & MPSM & 0.407 & MPSM & 1 \\
1.38 & ALSF & 0.3795 & ALSF & 0.394 & LAKS & 0 \\
1.38 & HBEF & 0.3779 & HBEF & 0.393 & ALSF & 0 \\
1.37 & LAKS & 0.3733 & LAKS & 0.387 & ASKF & 0 \\
1.36 & ASKF & 0.3625 & ASKF & 0.367 & NAFA & 0 \\
1.35 & NAFA & 0.3544 & NAFA & 0.359 & HBEF & 0 \\
1.32 & JSFE & 0.3188 & JSFE & 0.352 & JSFE & 1 \\
1.27 & JSLF & 0.2734 & JSLF & 0.315 & FHSF & 0 \\
1.27 & FHSF & 0.2672 & FHSF & 0.294 & JSLF & 0 \\
1.25 & FCMF & 0.2509 & FCMF & 0.265 & FCMF & 1 \\
1.21 & JSGF & 0.2125 & JSGF & 0.239 & JSGF & 1 \\
1.17 & USAF & 0.1701 & USAF & 0.172 & USAF & 1 \\
\hline & & & & & & \\
\hline
\end{tabular}

ings. The steepness of the omega function is a measure of its risk. Greater the steepness, less the risk (Keating and Shadwick, 2002)

Due to having nice three properties omega is well-suited for asset management. Firstly, as it includes all moments of the distribution, therefore, appropriate when returns are not normally distributed. Secondly, it allows investors preference of minimum acceptable return (MAR) as a result portfolio ranking will be different and rational than Sharpe ratio. Empirical results confirm that there is significant difference of ranking between Omega ranked portfolio and Sharpe ranked portfolio, for example table I shows that ranks of funds keep on changing with threshold, whereas, Sharpe ratio remains the same due to having no sensitivity to threshold. The minimum requirement for using Sharpe ratio is that returns distribution should be symmetric so that a unit of volatility means the same thing above and below the average (Cascon et al., 2006). In the previous section of normality tests we have already established that our data is non-normal and skewed in nature. Omega ratio exceeding 1 , indicates upside gains and Omega ratio less than 1 , indicates losses. If Omega ratio is equal to 1 , it is a condition when threshold is exactly equal to mean (Chen, 2016). 


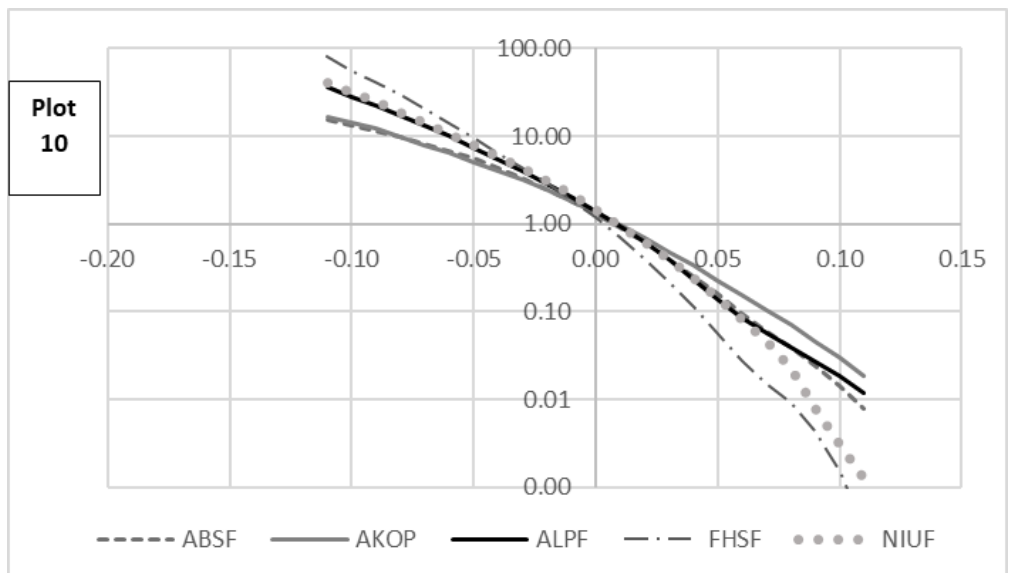

\subsection{Omega Function}

Omega ratio curve exhibits downward slopping curve which increases or decreases by varying threshold levels (MAR) i.e. at lowest MAR it yields highest Omega ratio and at highest MAR lowest Omega ratio. Therefore, in Omega function omega ratio is in continuous form (Van Dyk et al., 2014). In the following diagram on x-axis threshold values are chosen from the tabulation of the omega ratio at varying threshold. It holds three distinct properties, it is a decreasing function of threshold, value of omega ratio will always be 1 when threshold equals to mean and its shape makes risk profile clear (Cascon et al., 2006).

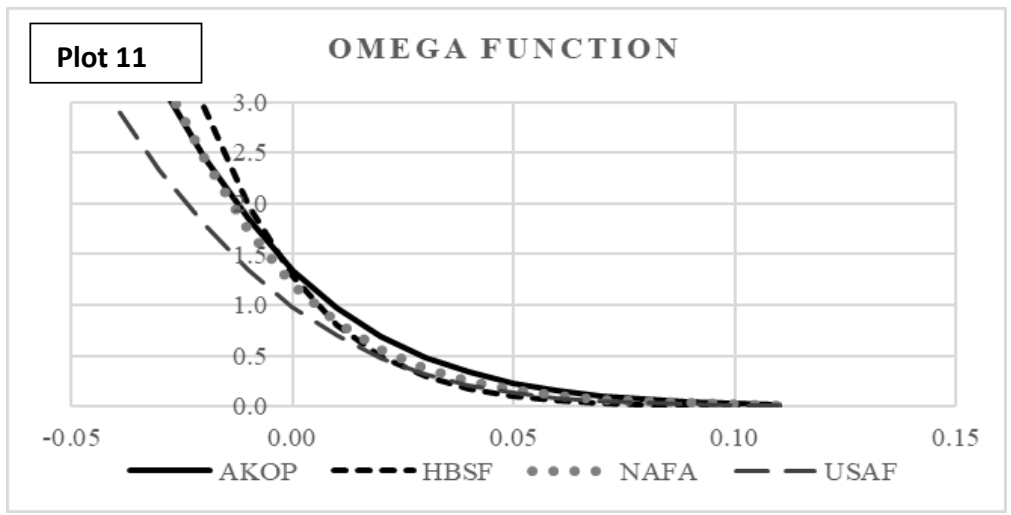

"When MAR is lower than the mean of distribution $\mu$, the Omega is higher than one $(\Omega>1$ when $M A R<\mu)$. The lower the MAR, the higher the probability to achieve it and thus the higher the Omega." (Steinki \& Mohammad, 2015)

Keating and Shadwick (2002) describes the Omega function as a probability adjusted ratio of gains to losses and say that, for a given threshold, the simple rule of preferring more to less implies that an asset with a high value of Omega is a better investment than one with a lower value. 


\section{Conclusion}

In Pakistan on directives of Securities and Exchange Commission of Pakistan (SECP), every AMC is required to report monthly Fund Managers Report and make it available on their website in a standardized format prescribed by Mutual Funds Association of Pakistan (MUFAP). Though, reporting risk measures such as Treynor Ratio and Sortino Ratio are voluntary for AMC as per MUFAP, however, all AMCs report their performances in Sharpe ratio. The current study proposed that,

1. Firstly, rolling returns should also be presented along with conventional annualized / cumulative or calendar years returns.

2. Secondly, Omega or Sharpe-Omega should also be included along with Sharpe ratio for better judgement of ranking if returns are not normally distributed as it is has been proved in this study.

This study provided room for academician and researcher to search what other performance measures can be taken up to calculate appropriate ranks of these AMCs when you encounter with non-normal return distribution.

\section{References}

Aggarwal, R., Rao, R. P., and Hiraki, T. (1989). Skewness and kurtosis in japanese equity returns: empirical evidence. Journal of Financial Research, 12(3):253-260.

Amin, G. S. and Kat, H. M. (2003). Hedge fund performance 1990-2000: Do the money machines really add value? Journal of financial and quantitative analysis, 38(2):251-274.

Arditti, F. D. (1967). Risk and the required return on equity. The Journal of Finance, 22(1):19-36.

Avouyi-Dovi, S., Morin, S., and Neto, D. (2004). Optimal asset allocation with omega function. Technical paper, Banque de France.

Bacmann, J.-F. and Scholz, S. (2003). Alternative performance measures for hedge funds. AIMA Journal, 1(1):1-9.

Bacon, C. R. (2008). Practical Portfolio Performance Measurement and Attribution, with CDROM. John Wiley \& Sons.

Bertrand, P. and Prigent, J. (2006). Omega performance measure and portfolio insurance. Thema University of Cergy, Working paper.
Bertrand, P. and Prigent, J.-1. (2011). Omega performance measure and portfolio insurance. Journal of Banking \& Finance, 35(7):1811-1823.

Bertrand, P. and Prigent, J.-L. (2014). French retail financial structured products: A typology and assessment of their fair pricing. Available at SSRN 2513231.

Bodie, Z. et al. (2009). Investments. Tata McGrawHill Education.

Boudt, K., Carl, P., and Peterson, B. G. (2012). Asset allocation with conditional value-at-risk budgets. Journal of Risk, 15(3):39-68.

Burrows, T. (2013). The managerial performance of mutual funds: an empirical study. PhD thesis, (C) Tim Burrows.

Caporin, M., Jannin, G. M., Lisi, F., and Maillet, B. B. (2014). A survey on the four families of performance measures. Journal of Economic Surveys, 28(5):917-942.

Caporin, M. and Lisi, F. (2009). Comparing and selecting performance measures for ranking assets. Available at SSRN 1393163.

Cascon, A., Keating, C., and Shadwick, W. (2006). The omega function-not for circulation. URL http://faculty. fuqua. duke. edu/charvey/Teaching/BA453. 
Chen, J. M. (2016). Sortino, omega, kappa: The algebra of financial asymmetry. In Postmodern Portfolio Theory, pages 79-105. Springer.

Cogneau, P. and Hübner, G. (2009). The 101 ways to measure portfolio performance. Available at SSRN 1326076.

Cootner, P. (1964). The random character of stock market prices cambridge.

De Wet, R., Krige, N., and Smit, E. (2009). Omega sharpens portfolio performance evaluation. USB Leaders Lab, 3(2):12-16.

Fama, E. F. (1965). The behavior of stock-market prices. The journal of Business, 38(1):34-105.

Feibel, B. J. (2003). Investment performance measurement, volume 116. John Wiley \& Sons.

Gandhi, R. K. and Perumal, R. (2016). Performance of selected bank mutual funds schemes impact in investors decision making,. International Journal of Advanced Research, 5(3):361-370.

Gaspars-Wieloch, H. (2015). Modifications of the omega ratio for decision making under uncertainty. Croatian Operational Research Review, 6(1):181-194.

Gay, C. E., Christensen, S. T., Hayward, G., Cielocha, S., and Binion, T. (2014). Systems and methods for processing additional distance units for distance-based insurance policies. US Patent App. 14/202,812.

Gupta, B. and Kazemi, H. (2008). Abnormal return patterns and hedge fund failures. Journal of Risk Management in Financial Institutions, 2(1):88-106.

Kapsos, M., Zymler, S., Christofides, N., and Rustem, B. (2014). Optimizing the omega ratio using linear programming. Journal of Computational Finance, 17(4):49-57.

Keating, C. and Shadwick, W. F. (2002). An introduction to omega. AIMA Newsletter.

León, A., Navarro, L., and Nieto, B. (2015). Dont stand so close to sharpe. In XXIII Finance Forum.

Nafees, B., Shah, S. M. A., and Khan, S. (2011). Performance evaluation of open end and close end mutual funds in pakistan. African Journal of Business Management, 5(28):11425-11434.

Razali, N. M., Wah, Y. B., et al. (2011). Power comparisons of shapiro-wilk, kolmogorov-smirnov, lilliefors and anderson-darling tests. Journal of statistical modeling and analytics, 2(1):21-33.

Shah, S. and Hijazi, S. T. (2005). Performance evaluation of mutual funds in pakistan. The Pakistan Development Review, 44(4):pp-863.

Steinki, O. and Mohammad, Z. (2015). Common metrics for performance evaluation: Overview of popular performance measurement ratios. Available at SSRN 2662054.

Van Dyk, F., Van Vuuren, G., and Heymans, A. (2014). Hedge fund performance using scaled sharpe and treynor measures. International Business \& Economics Research Journal (IBER), 13(6):1261-1300.

ZAIDI, S. Z. A. et al. (2017). Determinants of stocks for optimal portfolio. Pakistan Journal of Applied Economics, 27(1):1-27.

Zakamouline, V. and Koekebakker, S. (2009). Portfolio performance evaluation with generalized sharpe ratios: Beyond the mean and variance. Journal of Banking $\mathcal{E}$ Finance, 33(7):1242-1254. 


\section{Appendix 1 (Symbols used in this study)}

\begin{tabular}{|c|c|c|}
\hline Symbol & Fund Name & Inception Date \\
\hline INDX & KSE-100 Index & 1-Nov-91 \\
\hline ABSF & ABL Stock Fund & 28-Jun-09 \\
\hline AKOP & AKD Opportunity Fund & 31-Mar-06 \\
\hline ALPF & Alfalah GHP Alpha Fund & 9-Sep-08 \\
\hline ALSF & Alfalah GHP Stock Fund & 15-Jul-08 \\
\hline ASKF & Askari Equity Fund & 30-Mar-12 \\
\hline ATSM & Atlas Stock Market Fund & 24-Aug-04 \\
\hline FCMF & First Capital Mutual Fund & 24-May-95 \\
\hline FHSF & First Habib Stock Fund & 8-Oct-09 \\
\hline HBEF & HBL Energy Fund (Formerly: PICIC Energy Fund) & 20-Jan-06 \\
\hline HBEQ & HBL Equity Fund (Formerly: PICIC Stock Fund) & 20-Jan-06 \\
\hline HBSF & HBL Stock Fund & 23-Aug-07 \\
\hline JSFE & JS Value Fund & 14-Jan-96 \\
\hline JSGF & JS Growth Fund & 6-Jun-06 \\
\hline JSLF & JS Large Cap Fund & 15-May-04 \\
\hline LAKS & Lakson Equity Fund & 13-Nov-09 \\
\hline MPSM & MCB Pakistan Stock Market Fund & 11-Mar-02 \\
\hline NIUF & National Investment Unit Trust & 12-Nov-62 \\
\hline NAFA & NAFA Stock Fund & 22-Jan-07 \\
\hline USAF & UBL Stock Advantage Fund & 4-Aug-06 \\
\hline
\end{tabular}




\section{Appendix 2 (Rolling Returns)}
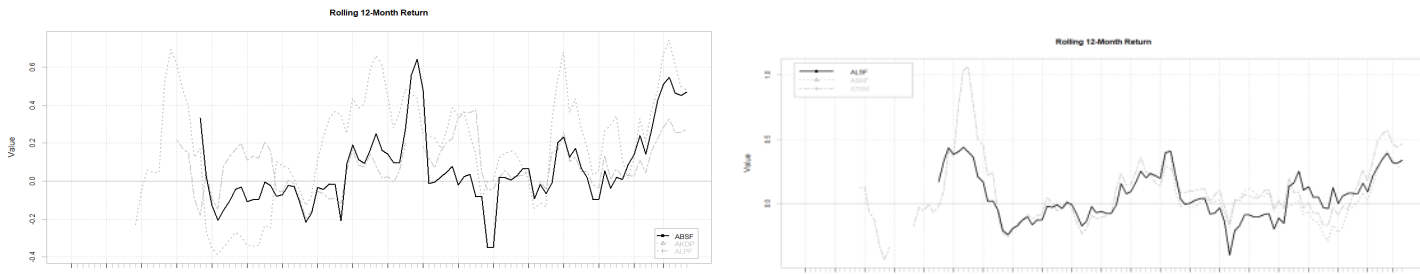

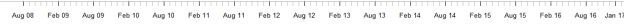
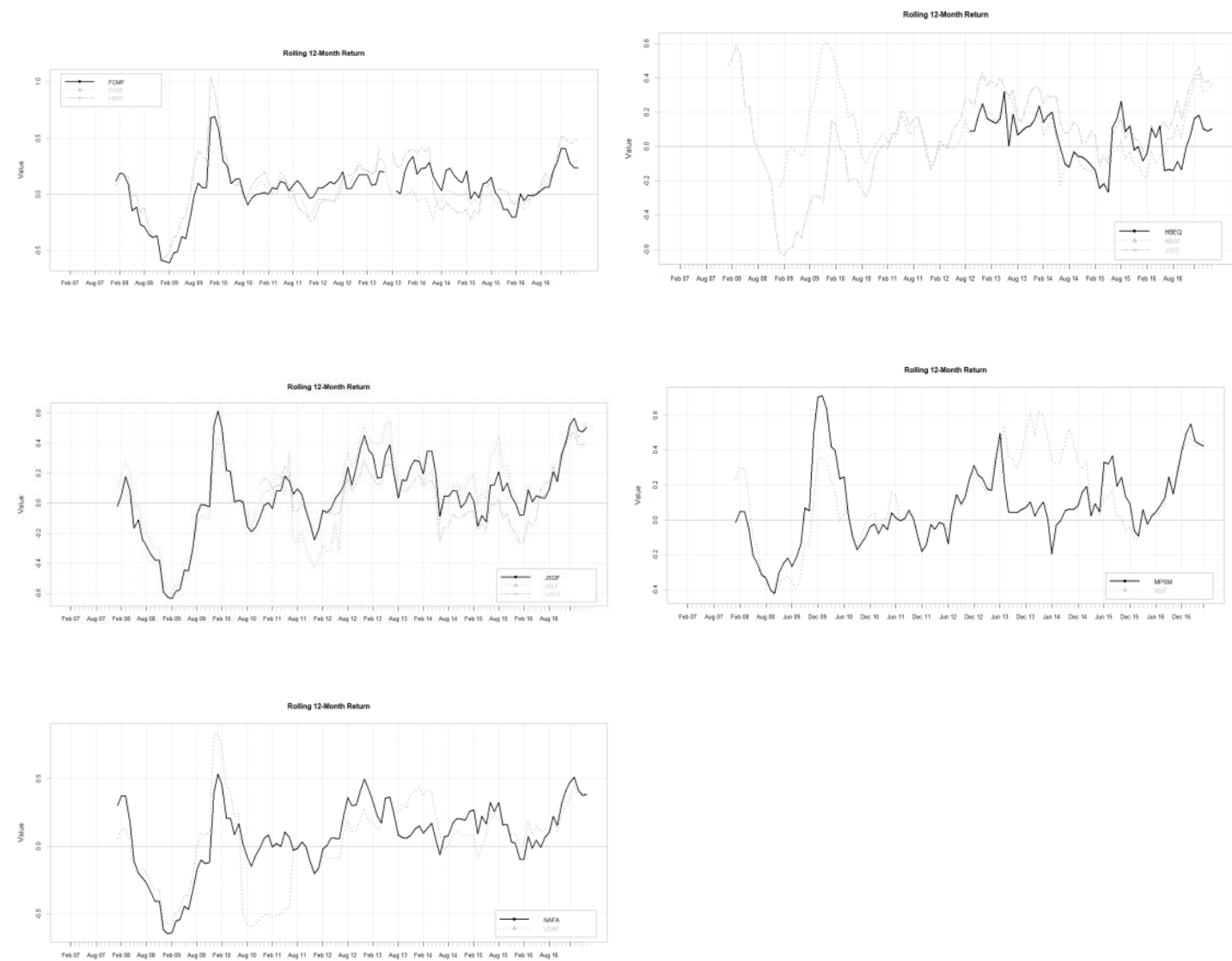


\section{Appendix 3 (Descriptive Statistics)}

\begin{tabular}{lcccccccccc}
\hline & INDX & ABSF & AKOP & ALPF & ALSF & ASKF & ATSM & FCMF & FHSF & HBEF \\
\hline nobs & 124 & 124 & 124 & 124 & 124 & 124 & 124 & 124 & 124 & 124 \\
NAs & 0 & 29 & 18 & 27 & 18 & 62 & 6 & 2 & 33 & 2
\end{tabular}

Minimum -0.3616 -0.3380 -0.3366 -0.2171 -0.3014 -0.1938 -0.2556 -0.3579 -0.1673 -0.3505

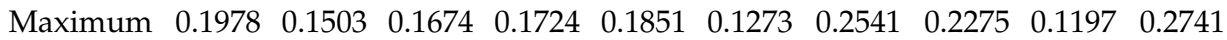

1. Quartile -0.0079-0.0189 -0.0149-0.0170 -0.0177-0.0083 -0.0143 -0.0176-0.0194-0.0136

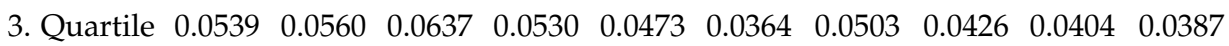
$\begin{array}{lllllllllll}\text { Mean } & 0.0146 & 0.0110 & 0.0127 & 0.0111 & 0.0081 & 0.0062 & 0.0091 & 0.0052 & 0.0047 & 0.0075\end{array}$ $\begin{array}{lllllllllll}\text { Median } & 0.0207 & 0.0243 & 0.0179 & 0.0184 & 0.0177 & 0.0166 & 0.0173 & 0.0120 & 0.0111 & 0.0130\end{array}$ $\begin{array}{llllllllllll}\text { Sum } & 1.8117 & 1.0452 & 1.3471 & 1.0724 & 0.8596 & 0.3872 & 1.0686 & 0.6286 & 0.4267 & 0.9095\end{array}$

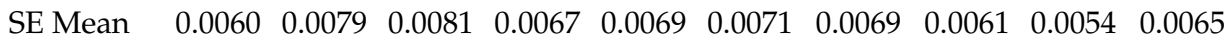

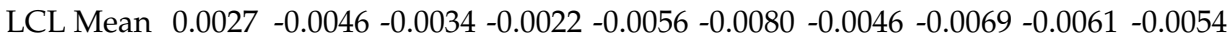

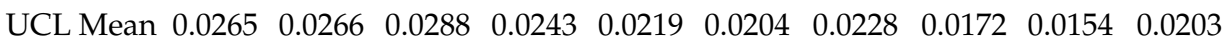
$\begin{array}{lllllllllll}\text { Variance } & 0.0045 & 0.0059 & 0.0070 & 0.0043 & 0.0051 & 0.0031 & 0.0056 & 0.0045 & 0.0027 & 0.0052\end{array}$ $\begin{array}{lllllllllll}\text { Stdev } & 0.0670 & 0.0765 & 0.0836 & 0.0658 & 0.0714 & 0.0559 & 0.0751 & 0.0674 & 0.0516 & 0.0719\end{array}$ Skewness $-1.6895-1.6876-1.3273-0.7276-1.2315-0.8513-0.7240-1.4624-0.7894-0.9646$ $\begin{array}{llllllllllll}\text { Kurtosis } & 7.5553 & 4.7846 & 3.8072 & 1.6387 & 3.6203 & 1.9632 & 2.2077 & 6.8931 & 0.9757 & 6.2713\end{array}$

\begin{tabular}{|c|c|c|c|c|c|c|c|c|c|c|}
\hline & HBEQ & HBSF & JSFE & JSGF & JSLF & LAKS & MPSM & NIUF & NAFA & USAF \\
\hline nobs & 124 & 124 & 124 & 124 & 124 & 124 & 124 & 124 & 124 & 124 \\
\hline NAs & 56 & 11 & 0 & 0 & 0 & 34 & 4 & 4 & 0 & 2 \\
\hline
\end{tabular}

Minimum -0.3097 -0.2795 -0.2438 -0.3517 -0.4068 -0.3110 -0.2867 -0.2375 -0.3688 - 0.5627

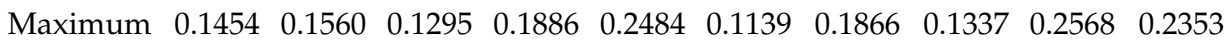
1. Quartile $-0.0157-0.0236-0.0237-0.0213-0.0224-0.0188-0.0126-0.0124-0.0195-0.0201$

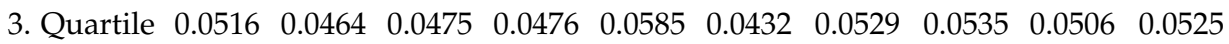
$\begin{array}{llllllllllll}\text { Mean } & 0.0087 & 0.0073 & 0.0065 & 0.0051 & 0.0072 & 0.0070 & 0.0083 & 0.0110 & 0.0078 & 0.0045\end{array}$ $\begin{array}{lllllllllll}\text { Median } & 0.0161 & 0.0117 & 0.0162 & 0.0120 & 0.0145 & 0.0165 & 0.0190 & 0.0150 & 0.0091 & 0.0170\end{array}$ $\begin{array}{lllllllllll}\text { Sum } & 0.5945 & 0.8208 & 0.8053 & 0.6317 & 0.8966 & 0.6293 & 0.9956 & 1.3152 & 0.9730 & 0.5489\end{array}$ $\begin{array}{lllllllllll}\text { SE Mean } & 0.0090 & 0.0055 & 0.0057 & 0.0066 & 0.0077 & 0.0065 & 0.0064 & 0.0057 & 0.0067 & 0.0082\end{array}$

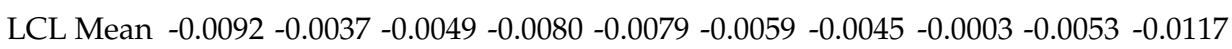

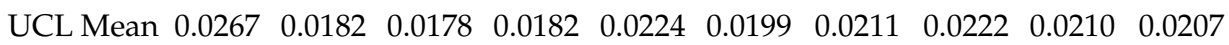
$\begin{array}{lllllllllll}\text { Variance } & 0.0055 & 0.0035 & 0.0041 & 0.0055 & 0.0073 & 0.0038 & 0.0050 & 0.0039 & 0.0055 & 0.0082\end{array}$ $\begin{array}{llllllllllll}\text { Stdev } & 0.0743 & 0.0589 & 0.0639 & 0.0739 & 0.0854 & 0.0615 & 0.0706 & 0.0623 & 0.0742 & 0.0906\end{array}$ Skewness $-1.8747-1.0767-1.2931-1.2119-1.4582-1.9421-1.1812-0.9651-1.0071-2.7124$ \begin{tabular}{lllllllllll} 
Kurtosis & 5.4473 & 4.0269 & 2.7869 & 3.9516 & 5.0117 & 6.8689 & 2.9920 & 1.6754 & 5.1321 & 13.6292 \\
\hline
\end{tabular} 


\section{Appendix 4 (Q-Q Plot of all Mutual Funds)}
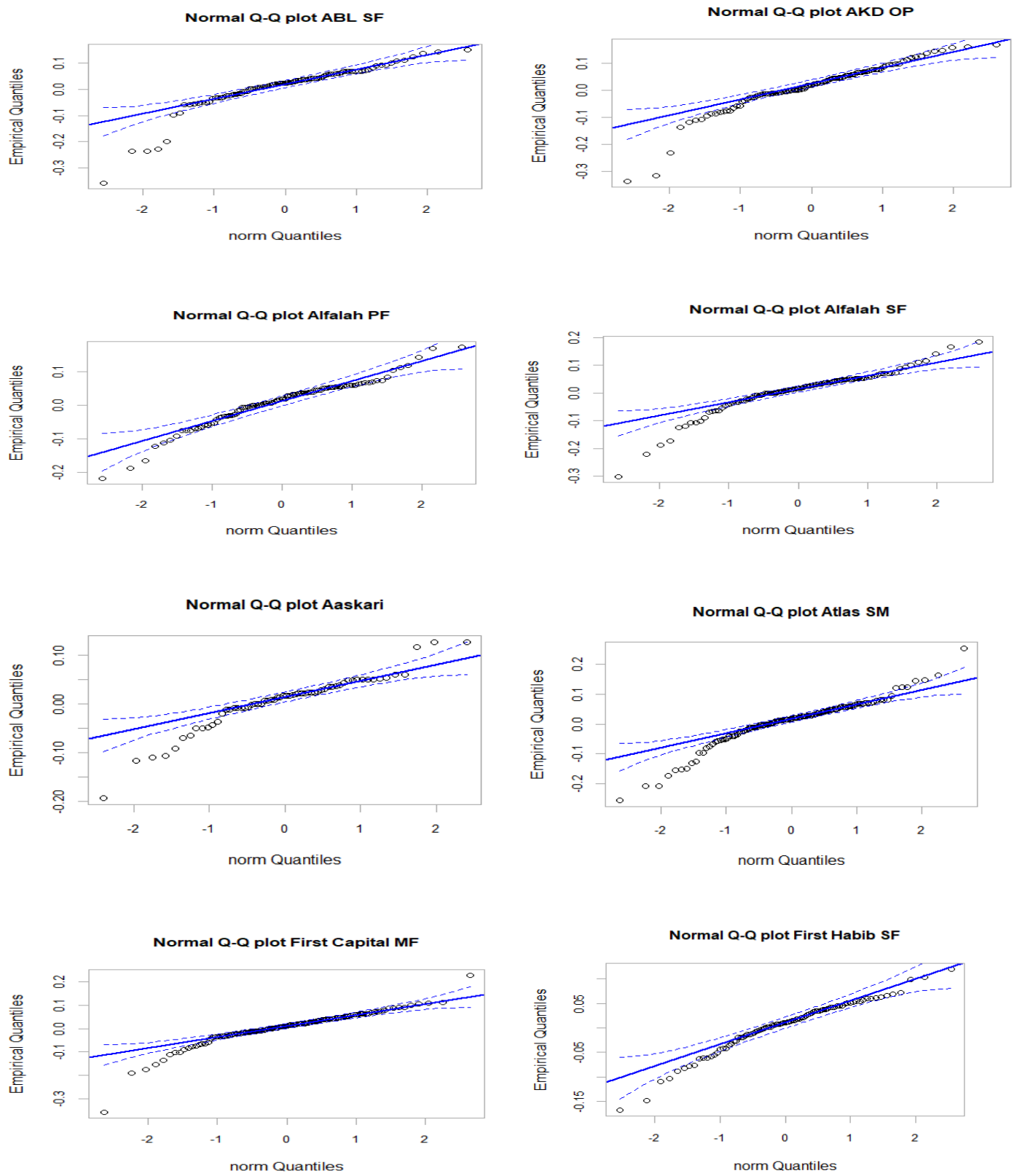

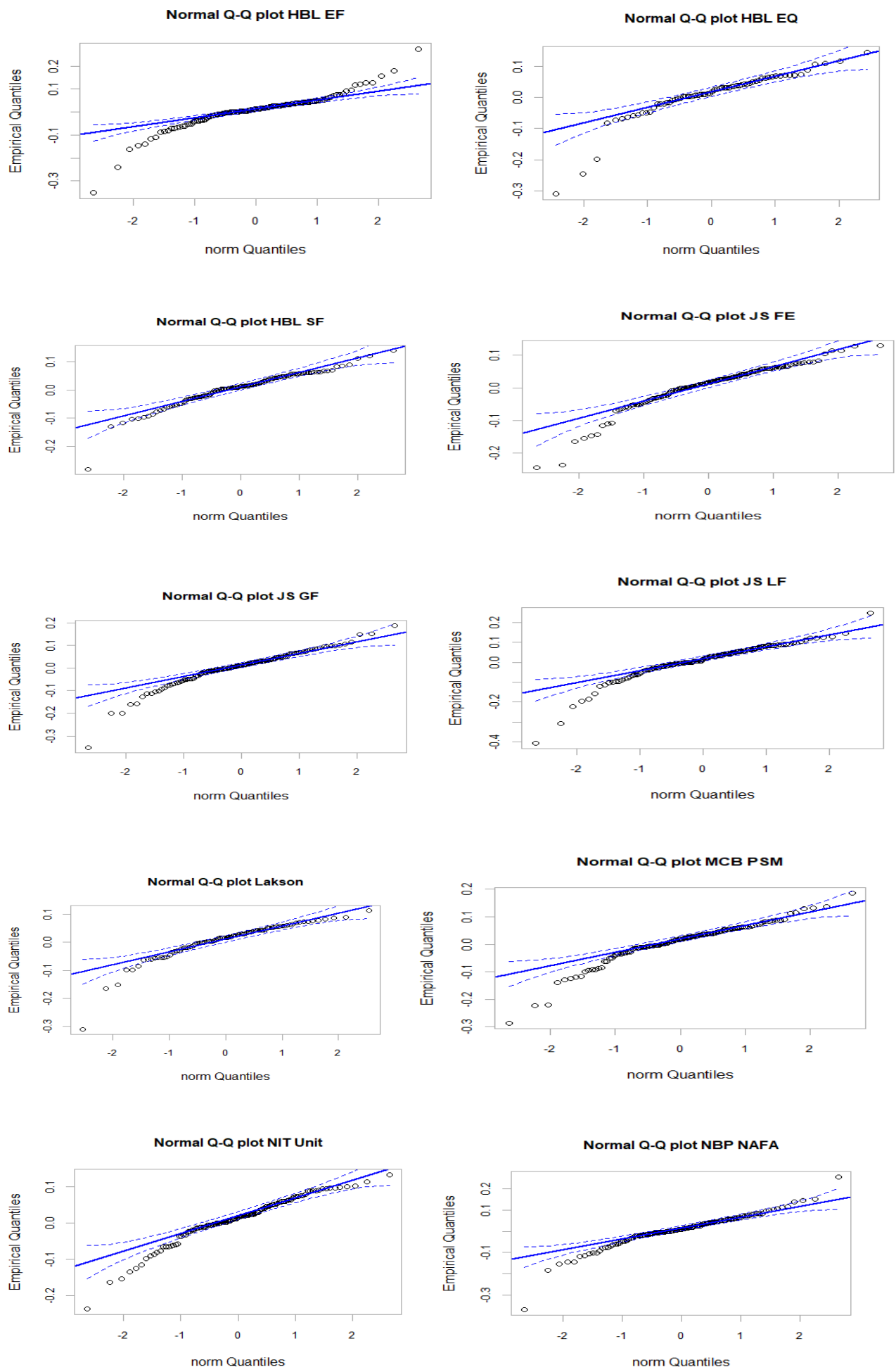
Normal Q-Q plot UBL SAF

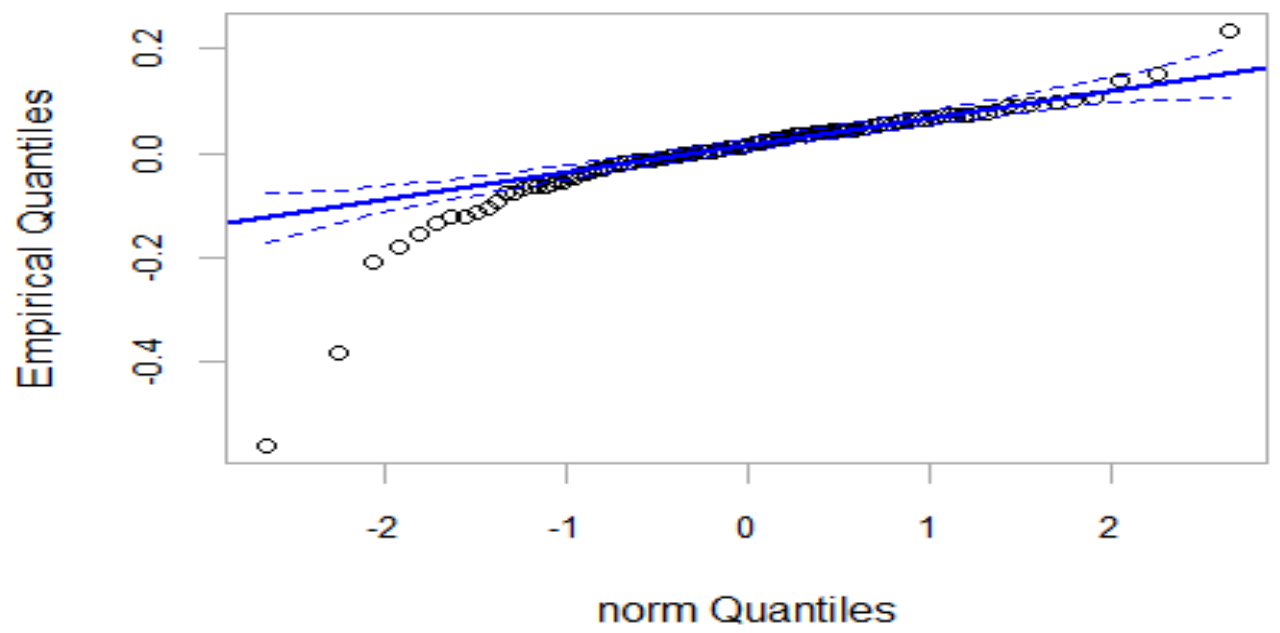

